\title{
Sensitivity analysis of emission factors for regional-scale nitrous oxide emissions estimates using NZ-DNDC
}

\author{
D. L. Giltrap ${ }^{a}$, K.P. Thakur ${ }^{a}$, and A.-G. Ausseil ${ }^{\mathrm{a}}$ \\ ${ }^{a}$ Landcare Research, Palmerston North, New Zealand \\ Email: giltrapd@landcareresearch.co.nz
}

\begin{abstract}
In the New Zealand Greenhouse Gas Inventory, the current method for calculating direct nitrous oxide $\left(\mathrm{N}_{2} \mathrm{O}\right)$ emissions from agricultural soils uses a constant emission factor (EF) multiplied by the nitrogen $(\mathrm{N})$ input from fertiliser and animal excreta. However, $\mathrm{N}_{2} \mathrm{O}$ emissions are actually the result of complex soil microbial processes, and soil properties, climate conditions and management practices can also influence emission levels. The National Inventory method is therefore limited in its ability to account for regional differences in $\mathrm{N}_{2} \mathrm{O}$ emissions resulting from differences in soil, climate and management practices.
\end{abstract}

An alternative approach to estimate emissions is the use of process-based models, such as DeNitrification DeComposition (DNDC). This model has been modified to take account of New Zealand soils, climate, and grazed pasture management (NZ-DNDC), and used to estimate anthropogenic $\mathrm{N}_{2} \mathrm{O}$ emissions at field- and regional-scale. As the model takes a long time to run when simulating a large number of points, multi-year NZ-DNDC simulations can be used to pre-generate $\mathrm{N}_{2} \mathrm{O}$ emission factors (EFs) with uncertainties. These EFs could then be linked to spatial units to upscale the estimation of nitrous oxide at regional- to nationalscale.

However, this generation of EFs implies a number of assumptions on the spatial unit homogeneity of soil, climate and farm practices. In this paper, we investigated the effects on the $\mathrm{N}_{2} \mathrm{O}$ EF of (a) variation in soil parameters, (b) variation in climate data, and (c) variation in stocking and fertiliser application rates on farms. This sensitivity analyses showed that EF was sensitive to changes in SOC, bulk density, $\mathrm{pH}$, rainfall, temperature, and solar radiation, with SOC being the most sensitive of these parameters. However, it was possible to spatially aggregate climate data without causing large errors in EF. Realistic management practices are more difficult to define as the model is unable to respond to events such as weather and pasture growth as farmers would in practice. However, it was possible to define ranges of fertiliser application and stocking rate ranges over which the EF did not vary more than $\pm 10 \%$ from the baseline value for the three farm types considered.

The proposed framework of EF generation will be able to be extended to other farm types, new management practices and mitigation strategies (e.g., the use of nitrification inhibitors, stand-off paddocks). It will enable quick assessments of regional and national-scale climate and land-use change scenario analysis.

Keywords: $\quad$ Greenhouse gases, NZ-DNDC model, sensitivity analysis, New Zealand 


\section{INTRODUCTION}

Nitrous oxide $\left(\mathrm{N}_{2} \mathrm{O}\right)$ is a potent greenhouse gas with a global warming potential 298 times higher than that of carbon dioxide (IPCC, 2007). $\mathrm{N}_{2} \mathrm{O}$ is formed in agricultural soils when $\mathrm{N}$ from fertiliser or animal excreta is broken down by soil microbes. $\mathrm{N}_{2} \mathrm{O}$ emissions from agricultural soils are a major source of greenhouse gas emissions in New Zealand, accounting for $13.5 \%$ of total greenhouse gas emissions Global Warming Potential basis (Ministry for the Environment, 2011). New Zealand currently calculates agricultural $\mathrm{N}_{2} \mathrm{O}$ emissions for the national inventory using a Tier II methodology whereby the total amounts of fertiliser and excretal $\mathrm{N}$ applied to soils are multiplied by country specific emission factors (EFs). However, as $\mathrm{N}_{2} \mathrm{O}$ emissions are actually the result of complex microbial processes, soil properties, climate conditions, and management practices can also influence emission levels. The National Inventory method is therefore limited in its ability to account for regional differences in $\mathrm{N}_{2} \mathrm{O}$ emissions resulting from differences in soil, climate and management practices.

There are both direct and indirect sources of $\mathrm{N}_{2} \mathrm{O}$ emissions from agricultural soils. Direct emissions refer to the $\mathrm{N}_{2} \mathrm{O}$ that is emitted at the original site of the $\mathrm{N}$ application, while indirect emissions arise from $\mathrm{N}$ that is transported via nitrate $\left(\mathrm{NO}_{3}{ }^{-}\right)$leaching or ammonia $\left(\mathrm{NH}_{3}\right)$ emission, and later produce $\mathrm{N}_{2} \mathrm{O}$ emission at another location. Indirect emissions cannot be directly measured on site, yet account for approximately $25 \%$ of $\mathrm{N}_{2} \mathrm{O}$ emissions from New Zealand agricultural soils (Ministry for the Environment, 2011). In this study we shall focus on direct $\mathrm{N}_{2} \mathrm{O}$ emissions only.

The direct EF is calculated according to equation (1). The $\mathrm{N}_{2} \mathrm{O}$ emissions in the absence of applied $\mathrm{N}$ (either fertiliser or animal excreta) are subtracted from the total $\mathrm{N}_{2} \mathrm{O}$ emissions, so the EF calculates the additional emissions arising from $\mathrm{N}$ addition. In this study we shall use a single $\mathrm{EF}$ to describe the combined effects of fertiliser and excretal $\mathrm{N}$ addition rather than using separate emission factors for fertiliser and excretal $\mathrm{N}$ applications.

$$
E F=\frac{\left(\text { Total } \mathrm{N}_{2} \mathrm{O} \text { emission }\right)-\left(\mathrm{N}_{2} \mathrm{O} \text { emission } \text { with } 0 \text { applied } \mathrm{N}\right)}{\text { Total } \mathrm{N} \text { applied }}
$$

Nitrous oxide emissions may also be calculated using process-based models that simulate the underlying soil physical, chemical and biological processes. One such model is DNDC (DeNitrification DeComposition, Li et al. 1992). DNDC has been adapted and applied in many different farm systems and countries at field and regional scale (Giltrap et al. 2010). In New Zealand, a modified version of the model (NZ-DNDC) has been used to model $\mathrm{N}_{2} \mathrm{O}$ emissions from dairy-grazed farms (Saggar et al. 2004), and $\mathrm{N}_{2} \mathrm{O}$ and $\mathrm{CH}_{4}$ fluxes from a sheep-grazed farm (Saggar et al. 2007a). NZ-DNDC has been found to produce $\mathrm{N}_{2} \mathrm{O}$ emissions that are within the uncertainty range of measured values. However, the model has not been well validated against other sources of N-loss (e.g. leaching, $\mathrm{NH}_{3}$ volatilisation) in New Zealand grazed pasture systems.

Giltrap et al. (2008) used the NZ-DNDC model to simulate net agricultural $\mathrm{N}_{2} \mathrm{O}$ emissions in the Manawatu-Wanganui region of New Zealand. However, there are some disadvantages in using the NZDNDC model at regional to national scale. First, it can take a long time to run a regional simulation when there are a large number of polygons, farm types and climate years to be considered. This makes it cumbersome for performing multiple scenario analyses. Second, the standard user interface is not easily integrated into other software (e.g. GIS applications). For these reasons Giltrap et al. (2011) proposed a framework for calculating agricultural $\mathrm{N}_{2} \mathrm{O}$ emissions at regional scale by pre-generating tables of EFs from multiple NZ-DNDC simulations over the range of major soil, climate and management conditions occurring in New Zealand. These EFs can then be linked to a GIS and used in scenario analyses. The EF can be multiplied by the spatially explicit nitrogen inputs (generated from land-use maps) to estimate $\mathrm{N}_{2} \mathrm{O}$ emissions (Figure 1).

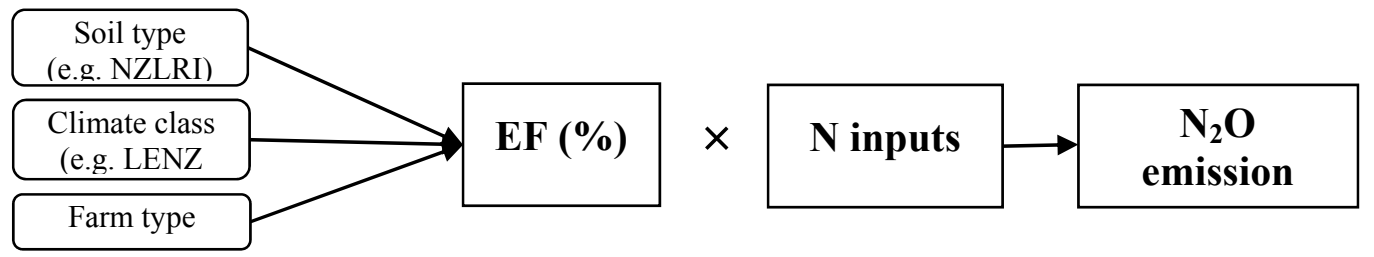

Figure 1: Schematic diagram of the proposed methodology.

In this paper, we perform sensitivity analyses of the EF to assess the uncertainties that could arise from the look-up tables. In particular, we focus on the sensitivity of EF to climate, soil, and management parameters. In addition, we tested the effect of upscaling EF over a climate region. 


\section{METHODOLOGY}

\subsection{Sensitivity of EF depending on climate, soil and management practices}

The simulations were performed using NZ-DNDC which is a modified version of DNDC8.6K. The major modifications are described by Saggar et al. (2004, 2007b). The sensitivity analyses were performed using climate data from a Manawatu farm for a single year (year ended June 2002), but for the purposes of generating EF tables a longer time period would be used. A start date of 1 July was used and it was assumed the soil was initially at field capacity. To calculate emission factors two simulations were run - one with excretal- and fertiliser-N added and a "background" simulation with no added excretal- or fertiliser-N.

The sensitivity analyses were performed by running simulations varying a single parameter at a time, while keeping all other parameters at a baseline value. This assumes that the parameters can be varied independently and that there is little interaction effect between parameters. Table 1 shows the baseline values and the range considered for the soil and climate properties. The baseline weather data was from a Manawatu farm for the year ended June 2002. The clay content was not varied as it is used to determine the soil texture class and there could be discontinuities at the boundaries between soil texture classes (as soil hydraulic parameters are read from files based on soil texture class). These baseline soil parameters represent mid-range values for a common soil type in the Manawatu-Wanganui region.

Table 1: Baseline values and ranges used for sensitivity analysis of soil and climate factors on EF

\begin{tabular}{|c|c|c|}
\hline Parameter & Baseline value & Simulated range \\
\hline Soil organic carbon (SOC) & $4 \%$ & $0.5-20 \%$ \\
\hline Clay content & $15 \%$ & Not varied \\
\hline Water-filled pore space at field capacity & $71 \%$ & Not varied \\
\hline $\mathrm{pH}$ & 5.8 & $4.5-8$ \\
\hline Bulk density & $1.06 \mathrm{~g} \mathrm{~cm}^{-3}$ & $0.8-1.5 \mathrm{~g} \mathrm{~cm}^{-3}$ \\
\hline Total rainfall $^{*}$ & $1142 \mathrm{~mm} \mathrm{y}^{-1}$ & $779-2857 \mathrm{~mm} \mathrm{y}^{-1}$ \\
\hline Mean annual temperature ${ }^{*}$ & $13^{\circ} \mathrm{C}$ & $1-30{ }^{\circ} \mathrm{C}$ \\
\hline Mean Solar Radiation $^{*}$ & $12.9 \mathrm{MJ} \mathrm{m}^{-2} \mathrm{y}^{-1}$ & $8.8-32.4 \mathrm{MJ} \mathrm{m}^{-2} \mathrm{~d}^{-1}$ \\
\hline Management practices & $\begin{array}{l}\text { Equal areas of dairy, deer, sheep and beef (intensive), } \\
\text { and sheep and beef (extensive) (Table 2) }\end{array}$ & See section 3.3 \\
\hline
\end{tabular}

${ }^{*}$ Based on daily data files of $\min / \max$ temperature, rainfall and solar radiation

Management practices are more difficult to determine from regional databases. We defined a number of "Farm types" as a set of common management practices (e.g. crop or stock type, grazing times and stocking rates, fertilizer timing and application). Additional farm types can be created to account for regional differences in management or adoption of mitigation practices. For this study we defined four farm types to cover the most common grazed farm systems: dairy, deer, intensive sheep and beef, and extensive sheep and beef. Table 2 shows the assumed stocking and fertiliser application rates for each system. Sensitivity analyses were then performed by changing the stocking and fertiliser application rates of each farm type.

Table 2: Assumed management practices by farm type

\begin{tabular}{|c|c|c|c|c|}
\hline Farm type & $\begin{array}{l}\text { Stocking rate } \\
(\text { head } / \mathrm{ha} / \mathrm{d})\end{array}$ & Grazing dates & $\begin{array}{l}\text { Fertiliser application } \\
(\mathrm{kg} \mathrm{N} / \mathrm{ha} / \mathrm{y})\end{array}$ & Application dates \\
\hline Dairy & 111.4 cattle & $\begin{array}{l}1 \text { Jan, } 12 \text { Feb, } 26 \text { Mar, } 7 \text { May, } 18 \\
\text { Jun, } 30 \text { Jul, } 10 \text { Sep, } 22 \text { Oct, } 3 \text { Dec }\end{array}$ & $\begin{array}{l}140 \text { (split between } 4 \\
\text { applications) }\end{array}$ & $\begin{array}{c}28 \text { Mar, } 9 \text { May, } 1 \\
\text { Aug, } 12 \text { Sept }\end{array}$ \\
\hline Deer & $6.25^{*}$ & Year round & 0 & $\mathrm{~N} / \mathrm{A}$ \\
\hline $\begin{array}{l}\text { Sheep and beef } \\
\text { (intensive) }\end{array}$ & $\begin{array}{l}0.66 \text { cattle } \\
7.9 \text { sheep }\end{array}$ & Year round & 15 & 1 Oct \\
\hline $\begin{array}{l}\text { Sheep and beef } \\
\text { (extensive) }\end{array}$ & $\begin{array}{l}0.51 \text { cattle } \\
6 \text { sheep }\end{array}$ & Year round & 7 & 1 Oct \\
\hline
\end{tabular}

${ }^{*}$ A deer was considered equivalent to two sheep

${ }^{* *}$ For the climate and soil properties sensitivity analysis two $60 \mathrm{~kg} \mathrm{~N} / \mathrm{ha}$ fertiliser were applied.

\subsection{Effects of up-scaling climate regions on EF}

Regional upscaling involves defining regions that can be treated as having spatially homogenous climate. To test this assumption 20 years of daily weather data were obtained from the Virtual Climate Station Network (VCSN) from NIWA (National Institute of Water and Atmospheric Research Ltd.). These data had been estimated for the whole of New Zealand on a $0.05^{\circ}$ latitude/longitude grid (Tait et al., 2006; Tait, 
2008; Tait and Liley, 2009). Giltrap et al. (2011) proposed dividing New Zealand into 16 climate zones based on Land Environments of New Zealand (LENZ) level 2 data (Leathwick et al. 2002). 1397 grid points corresponding to the largest of the proposed climate regions were selected and simulations run for the year ended June 1981 for each of the climate grid points as well as for the daily climate properties spatially averaged across the 1397 points.

\section{RESULTS}

\subsection{Effect of variability of climatic factors}

The weather file used by NZ-DNDC contains a daily record of the maximum and minimum temperatures, rainfall and solar radiation. Giltrap et al. (2008) found that inter-annual variations in weather caused a change in net $\mathrm{N}_{2} \mathrm{O}$ emissions of almost $20 \%$. For the look-up tables average EFs will be calculated using climate data from 1980 to 1999 . However, in this section we assess the EF sensitivity to each of the climate components (temperature, rainfall and solar radiation) separately. Rainfall and solar radiation were varied by multiplying the daily values by a constant. Temperatures were modified by adding or subtracting a constant to the minimum and maximum daily temperatures (Fig. 2a-c)

The $\mathrm{EF}$ had a maximum at $\mathrm{T}=23^{\circ} \mathrm{C}$, indicating the optimum temperature range for microbial activity (Fig. 2a). This temperature effect on EF matches the temperature effect on microbial reaction rates in the model. For $\mathrm{T}<3{ }^{\circ} \mathrm{C}$ the formation of ice in the soil changes the behaviour of EF (data not shown).

As denitrification is one of the major processes producing $\mathrm{N}_{2} \mathrm{O}$ in soil and occurs under anaerobic conditions, it is theoretically expected $\mathrm{N}_{2} \mathrm{O}$ emissions will increase with increasing soil moisture up to a maximum, then decrease as the $\mathrm{N}_{2} \mathrm{O}$ is denitrified to $\mathrm{N}_{2}$ at very high soil moisture. However, with rainfall a decreasing trend of modelled EF was seen (Fig 2b). This is because in the model rainfall was observed to influence not only the soil moisture, but also to increase $\mathrm{NO}_{3}{ }^{-}$leaching, reducing the amount of $\mathrm{NO}_{3}{ }^{-}$in the soil for $\mathrm{N}_{2} \mathrm{O}$ formation.

The EF increased with solar radiation up to around $19 \mathrm{MJm}^{-2} \mathrm{~d}^{-1}$, at which point the increase in EF levelled off (Fig. 2c). In the model, solar radiation affects the potential evapotranspiration on any given day. It was observed that when modelled levels of evapotranspiration were higher plant uptake of $\mathrm{N}$ (due to water stress) and $\mathrm{NO}_{3}^{-}$leaching (due to drier soils) were reduced resulting in higher $\mathrm{N}_{2} \mathrm{O}$ emissions. Actual evapotranspiration is limited by the availability of water in the soil, there is a point at which increases in solar radiation no longer produce any further increase in EF.

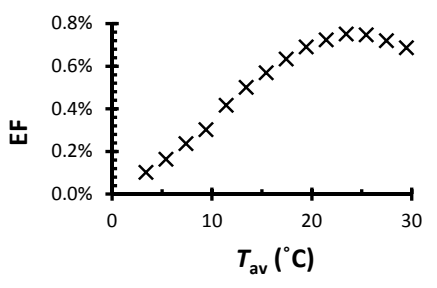

(a)

Figure 2. Variation of EF for a Manawatu soil as a function of change in (a) minimum and maximum temperatures, (b) average annual rain fall, and (c) Mean solar radiation for year ended June 2002.

\subsection{Effect of variability of soil parameters}

Simulations were run individually by varying SOC, $\mathrm{pH}$ and bulk density over the range of values given in Table 1 (Fig. 3a-c).

(a)

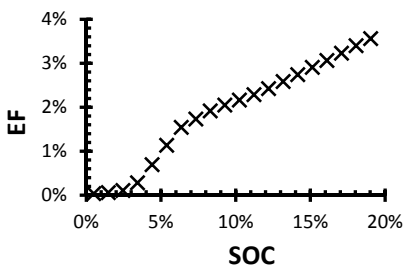

Figure 3. Variation of EF for a Manawatu soil as a function of change in (a) SOC, (b) pH, and (c) bulk density.

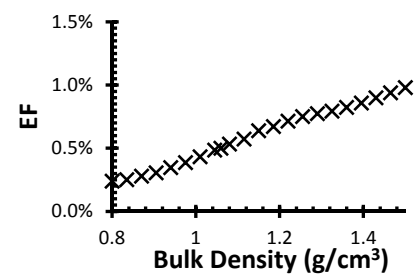

(c)

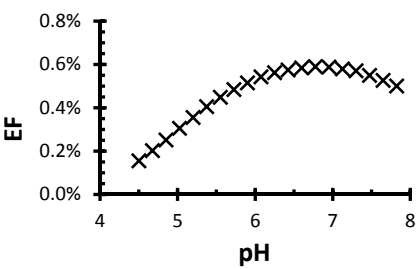

(b)

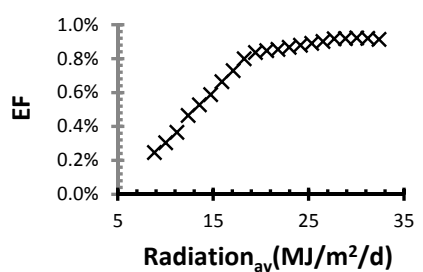

(c) 
The SOC results showed a persistent growth of EF with SOC, which agrees with the results of Li et al. (1996). Giltrap et al. (2008) found that increasing SOC could decrease net $\mathrm{N}_{2} \mathrm{O}$ emissions due to increasing background emissions, but this was not observed in this simulation. Here the effect of pasture removal by grazing cattle was included in the background simulation; not the case in Giltrap et al. (2008).

The $\mathrm{pH}$ results also showed a parabolic relationship with maximum $\mathrm{EF}$ at $\mathrm{pH}=6.8$, indicating an optimal $\mathrm{pH}$ for microbial activity. The bulk density results showed a nearly linear growth of EF with bulk density. The effect of bulk density is to increase the amount of SOC within a given volume of soil.

The sensitivity of variable $\mathrm{Y}$ with respect to $\mathrm{X}$ is defined as $\mathrm{d} \log (\mathrm{Y}) / \mathrm{d} \log (\mathrm{X})$, which is the $\operatorname{limit}$ of the ratio of the fractional change in EF to the fractional change in the parameter as the change gets very small. Of the parameters investigated, SOC was the most sensitive with a change in SOC producing almost 4 times the percentage change in EF (Table 3). None of the parameters investigated had a sensitivity close to zero, so the EF cannot be assumed to be constant with respect to changes in any of these parameters.

Table 3: Sensitivity of EF to variation in climate and soil parameters

\begin{tabular}{|l|l|c|c|}
\hline \multicolumn{1}{|c|}{ Parameter } & \multicolumn{1}{c|}{ Unit } & Baseline Value & Sensitivity $(\mathbf{d l o g}(\mathbf{Y}) / \mathbf{d l o g}(\mathbf{x}))$ \\
\hline $\mathrm{SOC}$ & $\%$ & 4 & 3.89 \\
\hline $\mathrm{pH}$ & dimensionless & 5.8 & 2.11 \\
\hline Bulk density & $\mathrm{g} \cdot \mathrm{cm}^{-1}$ & 1.06 & 1.70 \\
\hline Radiation & $\mathrm{MJ} \cdot \mathrm{m}^{-2} \mathrm{~d}^{-1}$ & 12.9 & 1.42 \\
\hline $\mathrm{T}_{\text {ave }}$ & ${ }^{\circ} \mathrm{C}$ & 13.4 & 1.08 \\
\hline Av. Annual Rain & $\mathrm{mm} /$ year & 1143 & -1.33 \\
\hline
\end{tabular}

\subsection{Effect of variability of management practices}

Table 4 shows the range of fertiliser application and stocking rates tested for dairy, sheep and beef (intensive), and sheep and beef (extensive) farms. ${ }^{1}$

Table 4: Baseline rates and ranges of fertiliser application and animal stocking for three farm systems

\begin{tabular}{|c|c|c|c|c|}
\hline Farm Type & $\begin{array}{c}\text { Baseline } \\
\text { Fertiliser } \\
(\mathrm{kg} \mathrm{N} / \mathrm{ha} / \mathbf{y})^{\mathrm{a}}\end{array}$ & $\begin{array}{c}\text { Fertiliser Range } \\
(\mathrm{kg} \mathrm{N} / \mathrm{ha} / \mathrm{y})^{\mathrm{a}}\end{array}$ & $\begin{array}{l}\text { Baseline Stocking rate } \\
(\text { head } / \mathbf{h a} / \mathbf{y})^{\mathbf{b}}\end{array}$ & $\begin{array}{l}\text { Stocking rate range } \\
(\text { head } / \mathbf{h a} / \mathbf{y})^{\mathbf{b}}\end{array}$ \\
\hline Dairy $^{c}$ & 140 & $40-200$ & 2.75 & $2-5$ \\
\hline Sheep and Beef (intensive) & 15 & $0-50$ & 13 & $5-20$ \\
\hline Sheep and Beef (extensive) & 7 & $0-50$ & 10 & $5-20$ \\
\hline
\end{tabular}

${ }^{a}$ Dairy farms split fertiliser application into 4 equal sized applications. Sheep and beef farms use single application

${ }^{b}$ Head of cattle for dairy farms and head of sheep for sheep and beef. 1 cattle produces an excretal-N loading equivalent to 7.25 sheep

${ }^{\mathrm{c}}$ Dairy cattle are rotationally grazed with 9 equally spaced grazing events throughout the year. Quoted stocking rate is the average over the year.

The effects of varying fertiliser and stocking rates on EF are shown in Figs 4 and 5 respectively. For all 3 farm types, the EF increases linearly with fertiliser application rate. For intensive and extensive sheep and beef the annual fertiliser application rate could be varied between 0-30 and 0-25 kg N/ha/y (respectively) while keeping the EF within $10 \%$ of the baseline value. For dairy farms the range was $\sim 110-160 \mathrm{~kg} \mathrm{~N} / \mathrm{ha} / \mathrm{y}$. However, this assumed that the extra fertiliser was applied by increasing the size of each fertiliser application. If, instead, the number of fertiliser applications was increased then the increase in EF due to increasing fertiliser application might be less.

For the grazing simulations on the dairy farm there were some grazing days when the pasture did not contain enough feed to support the specified number of animals. For those days, the number of animals was reduced to what the pasture could support and the excretal-N soil inputs calculated based on the actual stocking rate. The dairy pasture was not able to support more than $\sim 3$ cows/ha (Fig. 5a).

\footnotetext{
${ }^{1}$ Deer farms are very similar to intensive sheep and beef with no fertiliser input, and so were not simulated separately.
} 
(a)

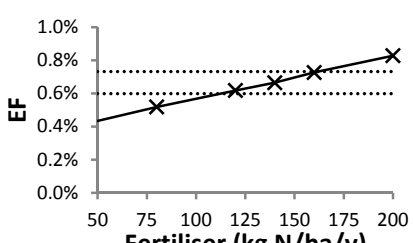

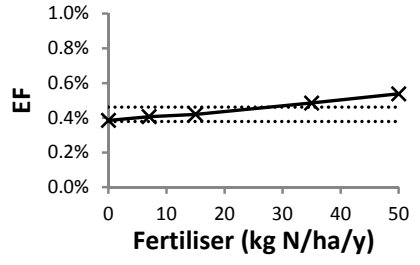

(c)

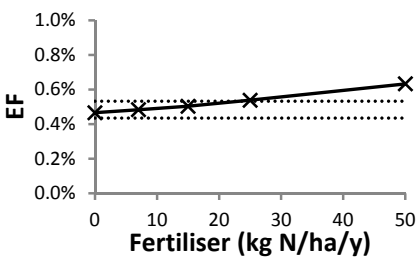

Figure 4: The effect of varying fertiliser application rates on $\mathrm{N}_{2} \mathrm{O}$ EF for (a) dairy, (b) intensive sheep and beef, and (c) hill country sheep and beef farms. The horizontal lines mark the region within $\pm 10 \%$ of the baseline EF

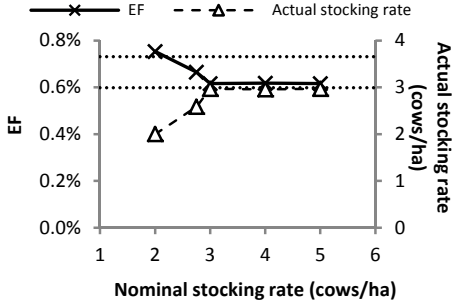

(a)

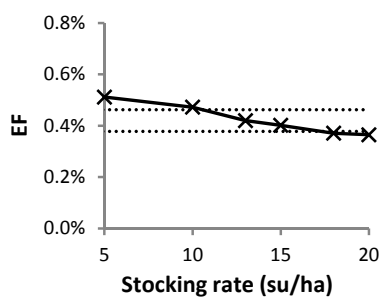

(c)

Figure 5: The effect of varying stocking rates on $\mathrm{N}_{2} \mathrm{O}$ EF for (a) dairy, (b) intensive sheep and beef, and (c) hill country sheep and beef farms. The horizontal lines mark the region within $\pm 10 \%$ of the baseline EF. su $=$ stock unit $(1$ sheep $=1 \mathrm{su}, 1$ cattle $=7.25 \mathrm{su})$

For all three systems the modelled EF decreased with increasing stocking rate. This was surprising as increasing animal numbers increases the excretal $\mathrm{N}$ inputs which should, if anything, increase the emission factor. However, these simulations involved changing the stocking rate without modifying any other management practices. At low stocking rates the pasture was under-utilised, so there was a large stock of standing grass resulting in less potential for plant uptake of additional $\mathrm{N}$ inputs and higher plant $\mathrm{N}$ inputs to the soil. Although net $\mathrm{N}_{2} \mathrm{O}$ emissions increased with increasing stocking rate, the rate of increase in net emissions was less than the rate of increase in applied $\mathrm{N}$ resulting in lower EF. This is an unrealistic situation as real farmers would make use of surplus production either by increasing stocking rates or by cutting the surplus grass growth to sell or use later in the year. Stocking rates cannot be considered independently of other management practices and soil and climate conditions. Therefore it is important to ensure that realistic management practices specified.

\subsection{Effects of up-scaling climate regions on EF}

The results are summarised in Table 5. The difference in EF between using the averaged climate data and taking the average of the 1397 points was relatively small ( $<4 \%$ change in EF). This gives some confidence that spatial averaging over a climate zone will not affect the predicted EF excessively.

Table 5: Results of the simulation of the 1397 different sites within a climate region compared with the averaged site (up-scaled)

\begin{tabular}{|l|c|c|c|c|c|}
\hline & Max Temp $\left({ }^{\circ} \mathrm{C}\right)$ & Min Temp $\left({ }^{\circ} \mathrm{C}\right)$ & $\begin{array}{c}\text { Annual Rain } \\
(\mathrm{mm})\end{array}$ & $\begin{array}{c}\text { Mean Radiation } \\
\left(\mathrm{MJ} / \mathrm{m}^{2} / \mathrm{d}\right)\end{array}$ & EF \\
\hline Minimum & 5.95 & 2.29 & 213 & 6.16 & $0.0022 \%$ \\
\hline Maximum & 9.60 & 5.20 & 2644 & 7.68 & $1.21 \%$ \\
\hline Average & 8.30 & 3.85 & 784 & 7.00 & $0.66 \%$ \\
\hline Std Dev & 0.52 & 0.49 & 203 & 0.24 & $0.17 \%$ \\
\hline Result using averaged climate data & 7.46 & 3.25 & 1045 & 7.28 & $0.69 \%$ \\
\hline
\end{tabular}

\section{CONCLUSIONS}

The $\mathrm{N}_{2} \mathrm{O}$ EF is sensitive to soil properties, climate and management practices. Sensitivity analyses showed that $\mathrm{EF}$ was sensitive to changes in $\mathrm{SOC}$, bulk density, $\mathrm{pH}$, rainfall, temperature, and solar radiation, with SOC being the most sensitive of these parameters. However, it was possible to aggregate climate data spatially without causing large errors in EF. 
It was possible to define ranges of fertiliser application and stocking rate ranges over which the EF did not vary more than $\pm 10 \%$ from the baseline value for each of the three farm types. This gives us a validity range for analysis of land-use intensification in our GIS framework. However, the model is unable to respond to events such as weather and pasture growth as farmers would in practice.

A further avenue of study would be to assess the effect of changes in the temporal distribution of weather and management events (e.g. changes in the frequency of rainfall or its distribution throughout the year, the effect of changing the number of fertiliser applications or grazing events).

\section{ACKNOWLEDGEMENTS}

This research was funded by the Ministry of Science and Innovation (MSI) - incorporating the former Foundation for Research, Science and Technology (FRST). Thanks to Anne Austin for editing and Kevin Tate for internal review.

\section{REFERENCES}

Giltrap, D., S. Saggar, C. Li, and H. Wilde (2008). Using the NZ-DNDC model to estimate agricultural $\mathrm{N}_{2} \mathrm{O}$ emissions in the Manawatu-Wanganui region. Plant and Soil, 309(1-2), 191-209.

Giltrap, D.L., C.S. Li, and S. Saggar (2010). DNDC: A process-based model of greenhouse gas fluxes from agricultural soils. Agriculture, Ecosystems \& Environment, 136(3-4), 292-300.

Giltrap, D., A.-G. Ausseil, K. Thakur, and S. Saggar (2011). A framework to estimate nitrous oxide emissions at regional and national scale. In: Adding to the knowledge base for the nutrient manager (Eds L.D. Currie and C L. Christensen). http://flrc.massey.ac.nz/publications.html. Occasional Report No. 24. Fertilizer and Lime Research Centre, Massey University, Palmerston North, New Zealand. 5 p.

IPCC (2007). Contribution of Working Group I to the Fourth Assessment Report of the Intergovernmental Panel on Climate Change. Cambridge University Press, Cambridge, UK. http://www.ipcc.ch/publications_and_data/ar4/wg1/en/contents.html

Leathwick, J., F. Morgan, G. Wilson, D. Rutledge, M. McLeod, and K. Johnston (2002). Land environments of New Zealand: A Technical Guide. Ministry for the Environment, Wellington, New Zealand. Available on-line at: http://www.landcareresearch.co.nz/databases/lenz/downloads/LENZ_Technical_Guide.pdf

Li, C.S., S. Frolking, and T.A. Frolking (1992). A model of nitrous-oxide evolution from soil driven by rainfall events. 1. Model structure and sensitivity. Journal of Geophysical Research-Atmospheres, 97 , 9759-9776.

Li, C., V. Narayanan, and R.C. Harriss (1996) Model estimates of nitrous oxide emissions from agricultural lands in the United States. Global Biogeochemical Cycles, 10, 297-306.

Ministry for the Environment (2011). New Zealand's Greenhouse Gas Inventory 1990-2009. Ministry for the Environment, Wellington, New Zealand. Available online: http://www.mfe.govt.nz/publications/climate/greenhouse-gas-inventory-2011/greehouse-gas-inventory2011.pdf

Saggar, S., R.M. Andrew, K.R. Tate, C.B. Hedley, N.J. Rodda, and J.A. Townsend (2004). Modeling nitrous oxide emissions from dairy-grazed pastures. Nutrient Cycling in Agroecosystems, 68, 243-255.

Saggar, S., C. Hedley, D.L. Giltrap, and S.M. Lambie (2007a). Measured and modelled estimates of nitrous oxide emission and methane consumption from a sheep grazed pasture. Agriculture, Ecosystems \& Environment, 122, 357-365.

Saggar, S., D.L. Giltrap, C. Li, and K.R. Tate (2007b) Modelling nitrous oxide emissions from grazed grasslands in New Zealand. Agriculture, Ecosystems \& Environment, 119, 205-216.

Tait, A. (2008). Future projections of growing degree days and frost in New Zealand and some implications for grape growing. Weather Climate 28, 17-36.

Tait, A., and B. Liley (2009). Interpolation of daily solar radiation for New Zealand using a satellite-derived cloud cover surface. Weather Climate 29, 70-88.

Tait, A., R. Henderson, R. Turner, and X. Zheng (2006). Thin-plate smoothing spline interpolation of daily rainfall for New Zealand using a climatological rainfall surface. International Journal of Climatology 26, 2097-2115. 